\section{THIS}

WORLD VIEW Did dislike of bland national foods drive obesity? p.149
EDITORIALS
DAM BUSTING Marathon journey

of Amazon catfish under
LAND-HO! SpaceX finally

lands its rocket on a base at sea $\mathbf{p} .152$

\title{
Breeding controls
}

\section{Scientists must help to inform regulators wrestling with how to handle the next generation of genetically engineered crops.}

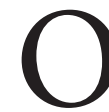
n 6 April, activists gathered in Paris to protest against an emerging class of genetically altered crops. Regulators often classify these as the product of 'new breeding techniques' (NBTs) that are sometimes distinct from classical - and historically controversial - genetically modified (GM) varieties. But some protesters, such as those who joined the Friends of the Earth demonstration in Paris last week, are unconvinced by that argument. They call the new plants 'hidden GMOs'.

Around the world, regulators are struggling to decide how to adapt the existing rules for transgenic technology to plant varieties that have been engineered using cutting-edge methods (see page 158). Many have found that their classical regulatory triggers rely on definitions of 'transgenic' or 'genetically modified organism' (GMO) that no longer apply. And they are questioning whether some NBT crops need to be regulated at all.

It is a complex problem, and one that demands steady input from researchers who are familiar with the science behind the technology.

Both terms - NBTs and hidden GMOs - attempt to hold an umbrella over a wide range of methods. Some of them are neither new technologies nor breeding techniques; many do diverge significantly from classical GM technology. The terms often apply to crops engineered using enzymes called nucleases that can be targeted to alter a specific DNA sequence, creating mutations or inserting new sequences into the genome. The wildly popular CRISPR-Cas9 gene-editing technique, for example, falls into this class. But the term NBT also refers to methods for silencing genes using RNA interference, for creating mutations without using nucleases, and even for grafting a non-GM plant onto a GM rootstock.

Public and regulatory discussions sometimes lump these techniques together, but the plants they yield can differ widely. Some mutations that are edited into the genome already exist in wild plant relatives in nature. Should such crops be regulated as stringently as crops in which CRISPR-Cas9 has been used to insert a fresh sequence into the genome? What if the insertion were 2 DNA letters, or 200?

It is clearly a challenge to gather all of this under a coherent regulatory framework that does not over- or under-regulate NBT crops. There will be a push for simplification. Researchers should seize every opportunity to inform the process, and to ensure that the simplification does not distort oversight.

The approach to oversight of GM crops at the US Department of Agriculture shows how a regulatory system can stray from science. GM crop regulations at that agency depend on its authority to control plant pests and noxious weeds. It is a system that had some relevance to the first generation of such crops, many of which were designed using genetic elements from plant pathogens.

It is rapidly losing relevance in the face of NBTs. In more than two dozen cases, the agency has determined that a particular NBT plant variety does not fall under its purview for regulation because it does

not entail the use of a plant pest and is unlikely to yield a noxious weed. These might have been scientifically sound decisions, but they were not made for scientifically sound reasons.

The agency is currently revisiting that regulatory structure. There is ample opportunity for scientists to participate: it has released a draft statement listing some of the regulatory possibilities, and the public can comment until 21 April (see go.nature.com/oftgcw). The US

"There is room for a healthy debate as to how these crops are regulated."
National Academies of Sciences, Engineering, and Medicine has convened a committee to evaluate future developments in biotechnology products, including engineered crops, and to examine how those developments could affect regulations. The report is likely to be influential, and scientists should take part in the discussions as much as possible.

Such opportunities are not limited to the United States: participation in other regions may not be as direct but could still be influential. Rather than wait on a long-delayed report from the European Commission to guide regulators, the European Plant Science Organisation in Brussels, for example, has already issued statements and put together educational material regarding NBTs (see go.nature.com/vcedfo).

There is room for a healthy debate as to how these crops are regulated: some may advocate for more oversight, others may want to loosen the reins. But for that debate to be fruitful, it must be well informed. Scientists with an interest in this field have a duty to ensure that it is.

\section{Under appeal}

\section{Don't get too excited about that successful appeal against a grant rejection.}

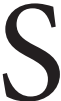
ince last week, Nature has been running an informal poll on its website, with striking results. Almost half of the thousand or so scientists who responded did not realize that it can be possible to appeal when they have a grant application rejected.

The poll was prompted by the remarkable story of a UK lab that successfully challenged such a rejection, and was subsequently awarded a $€ 5$-million (US $\$ 5.7$-million) grant. As we report on page 159 , computer scientist Peter Coveney at University College London convinced the European Commission that it had made a mistake in turning down his bid to create a hub to apply computer models to biomedical data.

"If your research is in jeopardy as a part of poor decisions, then people should be prepared to challenge them," Coveney said, in a 
rallying cry that will surely be applauded in labs across the world. What scientist does not feel wronged when their valuable contribution to society is not recognized and their application for funds spurned?

As inspiring as Coveney's victory may seem to the ranks of the downtrodden and unappreciated, his case is unlikely to produce a surge of similar appeal successes. For starters, the fact that many scientists who answered our online poll did not know about possible appeals processes has made little difference to them or to their fortunes. Many big funders, including several national agencies, don't allow appeals. Just like in sport, the referee's decision is final, however unjust it might seem. And for those agencies that do allow appeals (a good way to find out is to check the funder's website) any complaint must provide concrete evidence of an error. In Coveney's case, the European Commission had mistakenly marked his application down for including something it had asked for.

$\mathrm{Oh}$, and don't call your appeal a complaint. As many agencies even those that do permit appeals - make clear, they don't respond in the same way to complaints. (Some, however, do allow appeals against results of investigations into complaints.)

The US National Institute of Allergy and Infectious Diseases (NIAID), for one, says that it prefers to start by handling any appeal as a 'grievance', which is turned into an 'appeal' only if it cannot be resolved. In that case, an authorized organizational representative (AOR) must write to the relevant NIAID programme officer. If the programme officer, who maybe working with a scientific review officer, disagrees with the AOR, then NIAID will send the appeal to its advisory council, and then on to the National Institutes of Health's Center for Scientific Review. The principal investigator does not revise the rejected application, which is re-reviewed by either the same or a different scientific review group.
Confused? Any similarities between the complexity of some appeals processes and the way that rail companies, say, make the process to claim refunds for delayed services so complicated that most people don't bother are surely coincidental. And yet, back in 1987, an article in The Scientist pointed out that the formal process for appealing against rejected grants was "one of the best-kept secrets in the scientific community" and added, cryptically, that "science administrators seem content
"A successful appeal may not guarantee extrafunds." to leave it that way" (see go.nature.com/d99fc5).

The secret is out now, thanks to Coveney's efforts, and the decision in his favour announced last month. He and his co-applicants hired a lawyer to help them to negotiate the appeals process, but then the European Commission is known for its tortuous bureaucracy. Some research funders do, at least at first glance, seem to make the appeals process more benign. The British Academy, for example, simply invites those rejected to write to the chief executive, and then, as a last resort, to the president. Science Foundation Ireland intriguingly allows spurned applicants to appeal on the grounds of a wide range of possible failings in its procedures including the "inappropriate consideration of rumour/hearsay" by grant reviewers.

Be warned, though: a successful appeal does not guarantee extra funds. In its policy on grant-application appeals, the Natural Sciences and Engineering Research Council of Canada (NSERC) states: "If NSERC concludes that a procedural error occurred during the review of the application, the resulting funding decision could be to leave the original decision unchanged, or to increase or decrease the level and/or duration of the grant or award." Have appeals ever looked so unappealing?

\section{Destination Venus}

\section{Findings from the Akatsuki mission should rekindle interest in Earth's closest neighbour.}

$\mathrm{W}$ hen the first robotic probe penetrated Venus's cloud-filled atmosphere in 1967, it was designed to float. At the time, the surface of Venus was a complete mystery, and the engineers behind the Soviet Venera 4 thought it might land in a vast ocean. Science-fiction writers had imagined tropical swamps, forests or water worlds beneath the clouds. Venus's mass, density and composition were all similar to Earth's, and it was our closest neighbour, so it looked like a good bet for native life and even human colonization.

Instead, Venera 4 was destroyed before it reached the surface. The readout from its descent, and from subsequent probes, revealed extreme pressure, searing temperatures close to $500^{\circ} \mathrm{C}$ and an atmosphere that was $95 \%$ carbon dioxide. Even though Venus was originally very like Earth, perhaps even replete with oceans, a runaway greenhouse effect had turned it into a hellhole. No one, it seemed, would be going to holiday on Venus any time soon.

The discovery that the brightest body in the sky, bar the Sun and the Moon, is so hostile to life has helped to turn humanity's attention to Mars, our next-closest neighbour. Not only is the red planet a more viable candidate for an off-Earth base, it is much easier to study. On Venus, dense clouds of sulfuric acid mean that only radar can trace the surface from the air. Two rovers are trawling Mars right now, and more are in the pipeline; on Venus, probes designed to drop to the surface must deal with an environment that can melt metal.

So despite being the first planet to be visited by a probe, Earth's closest neighbour remains little-known. Venus's atmosphere contains a mystery substance, detected because it absorbs ultraviolet light, but so far unidentified. Scientists don't agree on how the planet's relatively young surface is remade, or how active its volcanoes are. The mechanism behind its enormous winds - which hit at several hundred kilometres per hour - is a mystery, as is why Venus rotates on its axis in the opposite direction to Earth. Does it have lightning? The jury is out.

Venus scientists feel that their planet is neglected. Despite a flurry of visits in the first decades of interplanetary exploration, NASA hasn't been to the planet since the Magellan mission ended in 1994. The European Space Agency's Venus Express orbiter filled a gap when it observed the planet from 2006 to 2014, but at $€ 220$ million (US\$252 million) it was a relatively small mission, and it could only peer at Venus from orbit.

Now, after a rocky journey, Japan's Akatsuki mission - which many wrote off as lost when its main engine failed in 2010 - has entered Venusian orbit and is revealing intriguing results about the planet's climate (see page 157). In its wake is another glimmer of hope: two Venus projects are among five proposals shortlisted for NASA's next \$500-million Discovery mission, launching in the early 2020s. VERITAS (Venus Emissivity, Radio Science, InSAR, Topography, and Spectroscopy) is a high-resolution radar mapper that would study the planet from the sky; the DAVINCI (Deep Atmosphere Venus Investigation of Noble gases, Chemistry, and Imaging) probe would sample the atmosphere during an hour-long plunge to the surface. Project leaders hope that compelling findings by Akatsuki will generate excitement about the planet at just the right time.

Given that life and the ability to sustain it will always be a selling point for an interplanetary mission, and that the only hope for life on Venus would be in its upper atmosphere, Venus's fall from favour might be understandable. But the planet holds a trump card. Increasingly, astronomers are searching for exo-Earths - extrasolar planets that, given their similarity to Earth, are a good bet for life. There, Venus can tell a cautionary tale. Despite starting out with all the ingredients for life, at some
DNATURE.COM To comment online, click on Editorials at: go.nature.com/xhunqv point Venus went rogue and became the hellish, acidic, dry planet it is today. Although life might not be found in a Venusian jungle, understanding why the planet took the path it did might be crucial to finding life elsewhere. 